El cuerpo del mundo en trescientas cajas. Los viajes estereoscópicos de Bernardo Croce (1910-1940)

Diego Guerra

Boletín de Arte (N. 20), e018, septiembre 2020, ISSN 2314-2502

https://doi.org/10.24215/23142502e018

http://papelcosido.fba.unlp.edu.ar/ojs/index.php/boa

Facultad de Artes. Universidad Nacional de La Plata

La Plata. Buenos Aires. Argentina

\title{
EL CUERPO DEL MUNDO EN TRESCIENTAS CAJAS
}

\section{LOS VIAJES ESTEREOSCÓPICOS DE BERNARDO CROCE (1910-1940)}

\section{THE BODY OF THE WORLD IN THREE HUNDRED BOXES}

\author{
BERNARDO CROCE'S STEREOSCOPIC TRIPS (1910-1940)
}

Diego Guerra / diegofernandoguerra76@gmail.com

Centro de Investigación en Arte, Materia y Cultura. Instituto de Investigación en Arte y Cultura Dr. Norberto Griffa. Universidad Nacional de Tres de Febrero. Argentina

\section{RESUMEN}

Hace algunos años fue hallada una colección de cinco mil placas estereoscópicas de vidrio de comienzos del siglo $X X$, pertenecientes a Bernardo Croce, médico y fotógrafo aficionado argentino. Las imágenes, producidas en el marco de la vida familiar, el ocio burgués y los viajes por el mundo, se inscriben históricamente en los inicios de la masificación de la fotografía y, a la vez, en la especificidad del sistema estereoscópico como vulgarización tardía de la reformulación epistemológica del estatuto de la visión en el siglo XIX. El presente artículo propone reflexionar, sobre el fenómeno de la estereoscopía y sus vínculos con el arte, la representación fotomecánica y la cultura de masas, así como sobre algunos problemas metodológicos planteados por este tipo de objetos en relación con su puesta en valor patrimonial.

\section{PALABRAS CLAVE}

Fotografía; estereoscopía; amateurismo; Argentina; Bernardo Croce

\section{ABSTRACT}

A few years ago, a collection of five thousand stereoscopic glass plates from the early 20th century was found in Buenos Aires. It belonged to late Bernardo Croce, an Argentine doctor and amateur photographer. The images, produced within the framework of family life, bourgeois leisure and world travel, are historically inscribed in the beginnings of the massification of photography and, at the same time, in the specificity of the stereoscopic system as a late vulgarization of the epistemological reformulation of the status of vision in the 19th century. This article proposes to reflect, on the phenomenon of stereoscopy and its links with art, photomechanical representation and mass culture, as well as some methodological problems raised by this type of object in relation to its patrimonialization.

\section{KEYWORDS}

Photography; stereoscopy; amateurism; Argentina; Bernardo Croce 
Hace algunos años, el desalojo de una casona centenaria en la ciudad de Buenos Aires propició el hallazgo de casi cinco mil placas estereoscópicas de vidrio y de un puñado de fotografías en papel de, aproximadamente, la primera mitad del siglo XX. Las imágenes fueron adquiridas, estabilizadas y catalogadas por el Centro de Investigación Fotográfico Histórico Argentino (CIFHA), donde se guardan actualmente.

Las fotografías pertenecían a Bernardo Croce, un (hasta entonces) ignoto médico y fotógrafo aficionado argentino, y fueron producidas -incluyendo una fracción minoritaria que no es de su autoría - en el marco de viajes y de actividades recreativas familiares entre las décadas de 1910 y 1930 . Así, el archivo responde a un abanico de intereses característicos de una época en la que tanto la fotografía como lo que ahora llamamos turismo se hallaban lejos de constituir una práctica masiva. Como otros profesionales cultos, de buena posición económica e interesado en las tecnologías modernas al alcance del usuario amateur, Croce fue un ávido coleccionista de imágenes que satisfacían una curiosidad geográfica, artística, arqueológica y etnográfica, compartida con numerosos fotógrafos aficionados dentro y fuera de la Argentina. Y más específicamente, la elección del sistema estereoscópico señala una fase tardía de la vulgarización de un divertimento óptico muy popular del siglo XIX, protagonista central del proceso de industrialización de la imagen fotomecánica, así como de la consolidación de la fotografía como herramienta moderna de apropiación de una realidad reconvertida, simultáneamente, en objeto de estudio científico y en espectáculo de masas.

El presente artículo propone reflexionar, a partir de este caso, sobre el fenómeno de la estereoscopía y sus vínculos con el arte, la representación fotomecánica y la cultura de masas, amén de algunos problemas metodológicos planteados por este tipo de objetos en relación con su puesta en valor patrimonial.

\section{ESTEREOSCOPÍA AMATEUR EN LA ARgENTINA}

El desarrollo de los dispositivos de visión estereoscópica fue correlativo al de las primeras técnicas fotográficas y se enmarca, como señala Jonathan Crary (2008), en un proceso histórico más amplio de reformulación del estatuto del observador y el modelo epistemológico de la mirada, que involucró al ámbito científico europeo durante el primer tercio del siglo XIX. En ese contexto, una vasta tratadística sobre temas como el color, la percepción visual y la anatomía ocular reorganizó las categorías de análisis en torno a un nuevo tipo de sujeto observador, condicionado por la fisiología de su aparato perceptivo y, a la vez, productor activo y autónomo de la experiencia óptica (Crary, 2008). En torno a estas nociones — que determinarían el estudio de fenómenos como la persistencia retiniana y el carácter subjetivo de la percepción del color, una de las claves de la pintura impresionista - tuvo lugar la producción de dispositivos que popularizaron la exploración lúdica de estos fenómenos, desde el caleidoscopio y el taumatropo hasta el visor estereoscópico.

Este último explotaba un fenómeno estudiado a mediados de siglo por Charles Wheatstone y David Brewster, basado en la capacidad del cerebro humano de conciliar las diferencias perceptivas resultantes de la disparidad de puntos de vista entre los ojos: de la superposición y fusión aparente de dos imágenes distintas, producto del paralaje binocular, resulta un efecto de tridimensionalidad que podía reproducirse artificialmente. Así, desde la década de 1850, la producción de vistas estereoscópicas mediante una cámara fotográfica de dos lentes, que simulaba tal paralaje, y de visores que ubicaban las imágenes a una distancia de los ojos que permitiera la superposición visual requerida impulsó una lucrativa industria, que contribuiría de modo decisivo a la popularización y la masificación internacional de las fotografías de paisajes, desnudos y otros géneros tan propicios a la ilusión de tangibilidad e intimidad que proporcionaba el dispositivo (Darrah, 1997).

En la Argentina fue el español Juan Camaña - el mismo que traería la novedad del copiado fotográfico a la albúmina- el primero en comercializar en Buenos Aires, desde 1852, 
daguerrotipos estereoscópicos cuyo elevado costo les dio una circulación muy restringida en un mercado reducido como el rioplatense (Becquer Casaballe \& Cuarterolo, 1983). Hubo que esperar hasta la última década del siglo para que la fase expansiva del modelo económico liberal y el desarrollo sostenido del mercado interno impulsado por la inmigración posibilitaran, junto con la creciente masificación del retrato fotográfico de estudio y la tarjeta postal, la popularización de las vistas estereoscópicas en nuestro país.

En este aspecto de la "segunda industrialización» de la fotografía (Tagg, 2005) jugó un papel fundamental el fenómeno del amateurismo fotográfico, emergente en la última década del siglo XIX y en cuya ulterior expansión en los sectores sociales medios y altos tomó parte el autor de las imágenes que nos ocupan. Como ha señalado Verónica Tell (2017), la creación de asociaciones y de publicaciones especializadas consolidó y dio visibilidad al fenómeno emergente de la fotografía estereoscópica amateur, en instancias como la exhibición de estereoscopías de la Sociedad Fotográfica Argentina de Aficionados en la Exposición Nacional de 1898 o las referencias al tema en las primeras revistas especializadas en fotografía del país.

Así, desde 1893 la estereoscopía fue un tópico recurrente en las páginas de la Revista Fotográfica llustrada del Río de la Plata, que con frecuencia traducía artículos técnicos provenientes de tratados incluidos en el catálogo de la importadora Lepage, editora de la revista. Es el caso de manuales como el Traité de Photographie Stéréoscopique [Tratado de fotografía estereoscópica], de Adolphe-Louis Donnadieu, publicado en 1892 y presente en dicho catálogo desde septiembre del año siguiente. Del mismo autor es el artículo dedicado a la distancia necesaria entre objetivos en las cámaras estereoscópicas, incluido en Les annales photographiques [Los anales fotográficos], cuya traducción se publicó en mayo de 1894 (Donnadieu, 1894). Otros números traían reseñas de artículos franceses, como el relativo al modelo de aparato estereoscópico de los hermanos Fleury (Revista de periódicos, 1894) y a tratados como el de Félix Drouin, comentado a pocas páginas de una nota sobre las ventajas de una prensa de corte para placas estereoscópicas de vidrio (Bibliografía, 1894; Prensa estereoscópica, 1894).

Aunque la producción estereoscópica atribuible a Croce es muy posterior a estas publicaciones, estos ejemplos señalan una primera instancia de circulación sostenida de conocimientos técnicos, insumos y equipos entre el público lector de revistas especializadas argentinas y europeas, que se prolongó en las décadas subsiguientes al calor del crecimiento del mercado fotográfico y la actividad amateur. En ese sentido, cabe mencionar los artículos que, desde fines de los años veinte, dedicó a estos temas la revista Foto-Magazine, como los Consejos a los estereoscopistas, de $\mathrm{H}$. Bourée o las indicaciones que el anónimo autor de Los anáglifos por virajes ofrecía a quienes desearan hacer fotografías estereoscópicas en color según el método patentado en 1891 por Louis Ducos du Hauron, y más tarde utilizado en el cine 3D (Boure, 1929; Estereoscopía, 1930).

Resulta interesante esa presencia — por lo demás, característica de la época- de un discurso técnico que vinculaba una tecnología heredada del positivismo decimonónico, reconvertida luego en dispositivo de entretenimiento de la industria cultural, en una revista concebida como el órgano de difusión de la Sección Fotografía de la Sociedad Estímulo de Bellas Artes, organizadora al año siguiente del primer Salón Internacional de Fotografía en Buenos Aires (Facio, 1995). La articulación de tan diversos espacios de legitimación institucional de la fotografía en una publicación que prolongó la circulación de saberes técnicos y de nociones estéticas en torno a la fotografía estereoscópica es ilustrativa del contexto histórico en el que Croce se desempeñó como coleccionista y autor aficionado de este tipo de imágenes. 


\section{BERNARDO CROCE Y SU COLECCIÓN}

En líneas generales, la trayectoria de Bernardo Croce (1881-1956) se ajusta a los imaginarios de ascenso social y de interés por los avances de la modernidad que atravesaban al sector social al que pertenecía. Profesional exitoso y primer universitario de una familia inmigrante, propietario de un amplio petit-hôtel en el barrio porteño de Belgrano, Croce fue un visitante asiduo de Europa y de Mar del Plata, a la vez que un prolífico fotógrafo y cineasta aficionado. Un evidente interés - tan caro a la inserción de la fotografía en la vida cotidiana del siglo XX (Sontag, 2006) - por dejar testimonio de su prosperidad y felicidad familiar determinó la producción de un vasto archivo de imágenes, del que sobrevive un total de 4867 fotografías estereoscópicas en vidrio (casi todas en negativo) y una veintena de copias positivas en papel.

En uno y otro soporte - a lo que se agrega un número incierto de filmaciones en $16 \mathrm{~mm}$, hoy perdidas ${ }^{1}{ }^{1}$ la temática es la habitual en este tipo de registro: viajes por el país y al extranjero, en un arco geográfico que va de Uruguay a China, África y Europa. Destinos obligados como Francia, Italia o Alemania suman otros más exóticos como la Península Escandinava, Hungría o Checoslovaquia, amén de colonias europeas en África, en Cercano Oriente y en el Sudeste Asiático. La diversidad de temas es característica y abarca paisajes, arquitecturas emblemáticas por su importancia histórica o su carácter innovador (como la vista de Río de Janeiro desde el Bondinho, recién construido, o el interior del Coliseo Romano); construcciones de infraestructura portuaria, caminera o ferroviaria que dan cuenta de la transformación del paisaje por la modernidad [Figuras 1 y 3]; salas de museos y monumentos públicos [Figura 5]; rituales, fisonomías y escenas cotidianas de tribus asociables al estereotipo del salvaje [Figura 2]; retratos del autor o sus acompañantes en situaciones diversas, y también registros de actualidad, como la Gran Guerra, la visita del príncipe de Gales a Buenos Aires o las multitudes de la Italia fascista.

De esta rápida lista se desprende una inclinación, tan recurrente como típica de esta clase de registros, hacia temas que visibilizan las tensiones entre modernidad y tradición, tanto en la mirada proyectada sobre culturas primitivas — caso de los "adoradores del diablo" de la actual Sri Lanka [Figura 2] - como en el puente ferroviario de Cipolletti a Neuquén, construido en 1901. En este [Figura 1] el imaginario persistente del avance de la civilización sobre el desierto es visible en el contraste que ofrecen la verticalidad del molino y la monumental estructura geométrica de acero frente a la desnudez del paisaje; pero también, en la observación específica sobre su escala («tiene 600 metros») anotada directamente sobre la imagen.

Es curiosa la frecuencia con que Croce añadía comentarios manuscritos de este tipo: no ya en los márgenes o en la zona central del par estereoscópico, donde quedaban fuera del campo visual del observador, sino directamente en una de las dos imágenes, en zonas claras donde fueran bien legibles (como los cielos) de modo tal que se integraran a la composición como un elemento visual más, que el efecto tridimensional iba a mostrar en primer plano. El interés por añadir estos anclajes textuales de sentido — cuya función, señalaría poco después Walter Benjamin [1936] (1989), es inseparable de la impronta documental de la fotografía - se evidencia en los casos en que el autor, como en la Figura 3, eligió rayar el negativo del lado de la emulsión, lo que lo obligaba a escribir de derecha a izquierda dando como resultado una letra vacilante que evidentemente lo llevó a abandonar esa opción en casos ulteriores.

1 Agradezco por estas referencias a Guillermo Buck, amigo de los Croce, que colaboró en el hallazgo del archivo; así como a Alfredo Srur, director de CIFHA, por facilitar el material para esta publicación. 


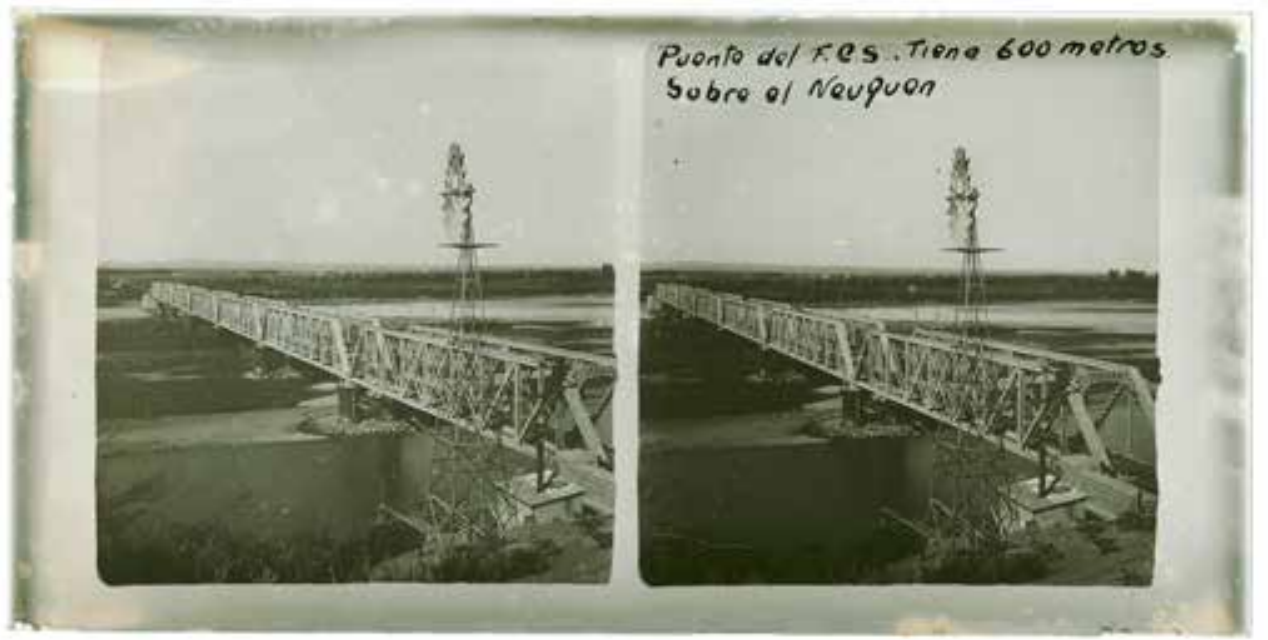

Figura 1. Puente del F. C. S. sobre el Neuquén. Tiene 600 metros (s. f.), Bernardo Croce (c. 36, pl. 13). Fuente: Archivo CIFHA

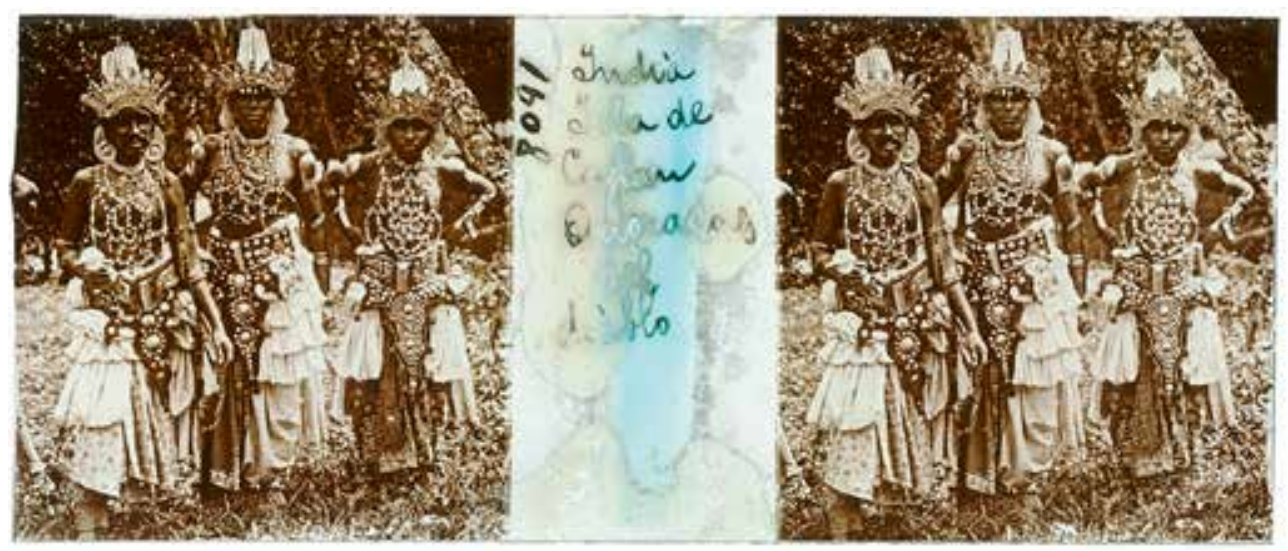

Figura 2. 8091 India. Isla de Ceylán. Adoradores del diablo (s. f.), Anónimo (c. 23, pl. 20). Fuente: Archivo CIFHA

En relación con el carácter de inscripciones autorales que podría asimismo atribuirse a estas anotaciones (Tell, 2017), no está claro qué porcentaje exacto de estas imágenes fueron realmente realizadas por Croce y cuántas fueron compradas, aunque la gran mayoría parece pertenecer a la primera categoría. Unas doscientas llevan el sello de Vérascope Richard, fabricante francés de equipos y placas estereoscópicas cuyas imágenes coloniales de Asia y de África, así como de otros destinos presentes en esta colección como Sidney o La Habana, invadieron el mercado internacional de la época. Otras, que parecen de otros autores, perdieron el sello, pero registran situaciones en las que claramente Croce no estuvo, como la Primera Guerra Mundial, y pueden haber sido adquiridas en viajes posteriores o incluso en Buenos Aires.

En cualquier caso, el médico organizó la colección bajo un sistema de notación propio, basado en un código alfabético o numérico (según el caso) que escribía al margen de numerosas placas al parecer de su autoría [Figuras 4 y 5], así como al exterior de las cajas originales, donde las enlistaba minuciosamente. El sentido de esta notación permanece indescifrado, por cuanto ubica en numeraciones correlativas a fotografías de distintas locaciones y fechas - con frecuencia, también consignadas en la placa- y, a la vez, contradice la articulación aparente entre imágenes producidas consecutivamente, pero ubicadas en cajas diferentes. Una hipótesis posible es que Croce, al organizar la guarda de las placas en sus cajas de fábrica, se desentendiera deliberadamente de toda continuidad temática o temporal para ordenarlas por series visualmente heterogéneas, de 20 a 25 unidades por caja y listas para ser colocadas en el visor para su observación. 
Si esta organización del archivo dificulta considerablemente su ordenamiento cronológico general, en todo caso es claro que la habilidad técnica de Croce se mantiene relativamente pareja a lo largo de las tres décadas en que se inscribe su producción. Ello implica la realización de fotografías extraordinariamente logradas, en algunos casos, en términos compositivos, pero también de foco y de tiempo de exposición: este último, un tema particularmente sensible en las tomas de interiores, como se ve en la Figura 5 donde una inevitable sobreexposición afecta a las zonas más claras dadas por el mármol de las estatuas; no obstante, el fotógrafo obtuvo una perfecta inmovilidad en las figuras del artista y de la mujer sentada a su lado. En cuanto a lo compositivo, la principal dificultad estaba dada por la necesidad, propia del dispositivo estereoscópico, de incluir un cierto número de objetos en primer plano y a distancias intermedias, de modo que los cambios en el ángulo de convergencia de los ejes ópticos entre un objeto y otro acentúen la sensación de profundidad.

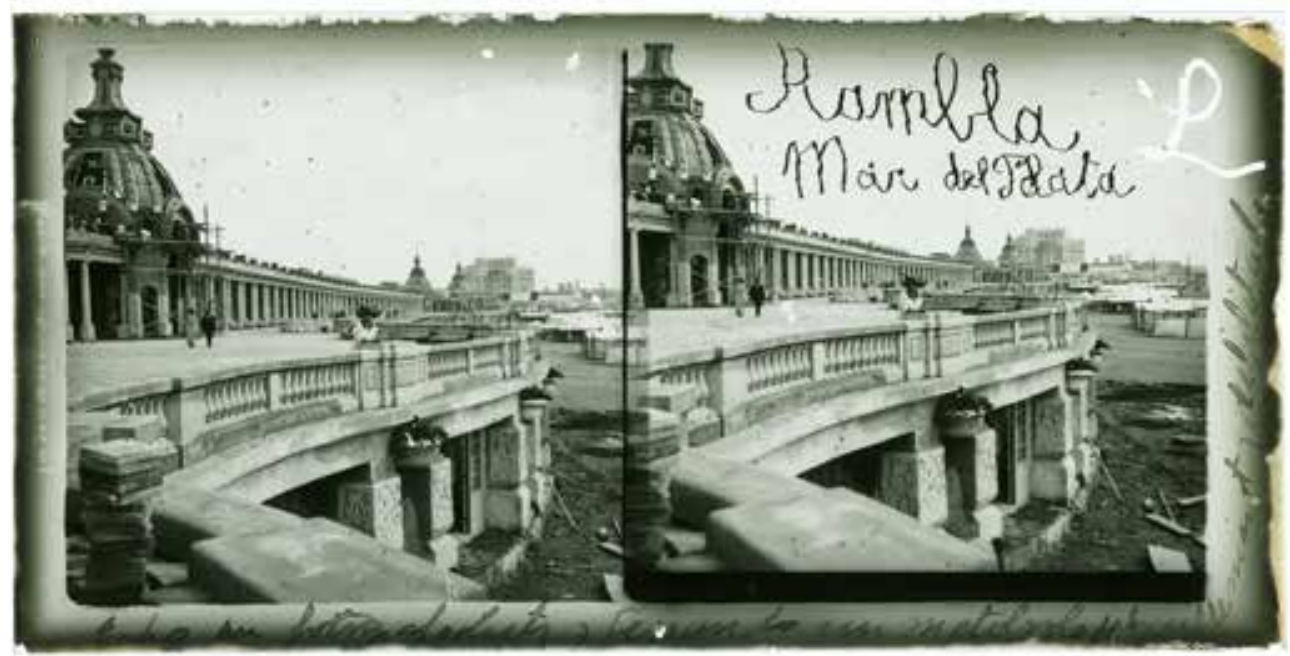

Figura 3. Rambla Mar del Plata (1913), Lutz y Ferrando o Bernardo Croce (c. 40, pl. 12). Fuente: Archivo CIFHA

Parece claro que Croce, en ese aspecto, aprendió de las estereoscopías comerciales a capitalizar compositivamente las fugas de ciertos elementos que enmarcan o estructuran la escena -edificios, trenes, calles, barcos-, así como la presencia a distancias variables de objetos y personas que completan el efecto de contraste. Es ejemplar en ese sentido la vista de la estación ferroviaria de Génova [Figura 4]: tomada en dirección longitudinal al andén, la pronunciada fuga de este, los trenes y el techo hacia el centro de la composición establece una perspectiva cuya profundidad completa el ojo del observador por la distancia ilusoria entre el fondo de la estación y el poste eléctrico ubicado al centro, en primer plano. En ese espacio virtual se ubican figuras — un maquinista, guardas, maleteros y pasajeros - que transitan, leen el diario o posan mirando a cámara y reforzando, por su interpelación directa al espectador, la sensación de distancia física variable respecto de este. La carretilla de madera a la derecha - un arcaísmo que contrasta, en escala y aspecto, con la modernidad decimonónica de la estación - ofrece un anclaje visual en primer plano y contrapesa compositivamente la proyección fuera de cuadro de la locomotora a la izquierda. 


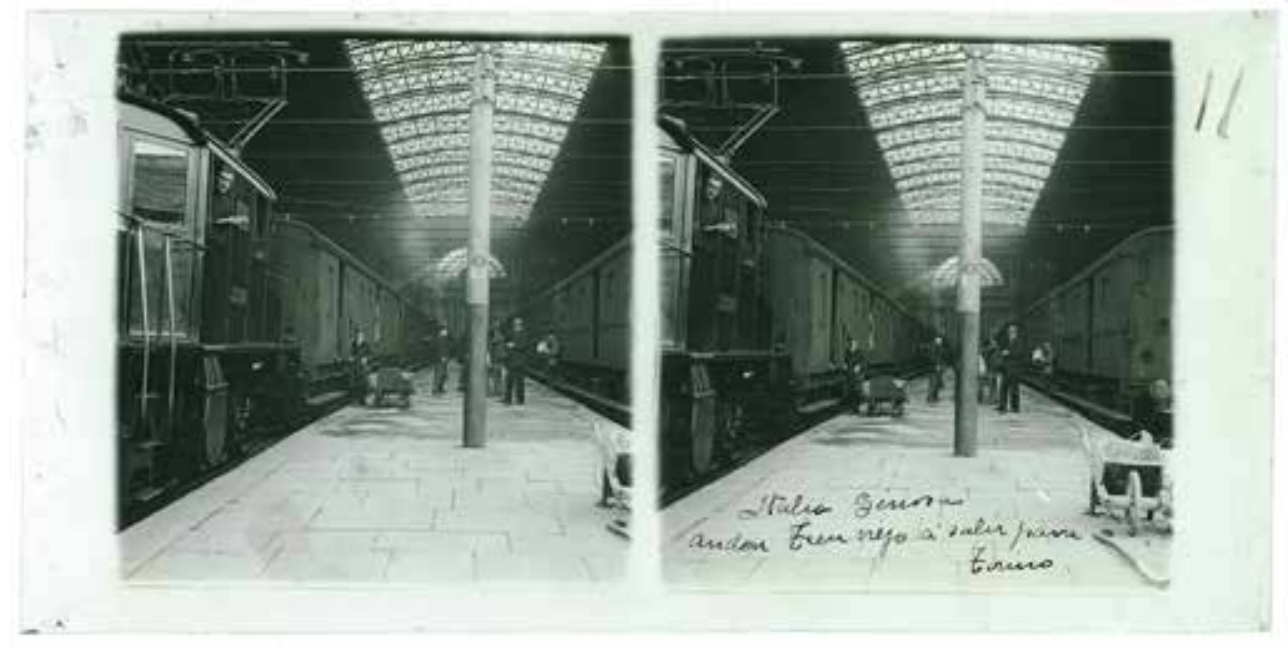

Figura 4. 11 Italia, Génova. Andén tren viejo a salir para Torino (s. f.), Bernardo Croce (c. 88, pl. 7). Fuente: Archivo CIFHA

Recursos compositivos y estéticos de esta índole habían sido desarrollados y estandarizados desde el siglo XIX, cuando quedó claro que la resolución visual más exitosa de la fotografía estereoscópica se producía en el horror vacui de las escenas con «interiores abarrotados de curiosidades [...], salas de escultura de museos repletas y vistas urbanas congestionadas" (Crary, 2008, p. 165). Algo de ello perdura en las placas de Croce cuando registran naves de iglesias, salones de fiestas y museos de arte, de antropología o de ciencias naturales. Las esculturas, máscaras exóticas, cabezas reducidas o animales disecados se ubican de manera de proyectarse acusadamente hacia el espectador: así ocurre, por ejemplo, con la sala de Villa Borghese donde un artista copia el Amor sagrado y amor profano de Tiziano [Figura 5]. La práctica registrada en esta toma - la copia de obras maestras como instancia de aprendizaje del pintor - ratifica, de paso, el papel de la pintura del Alto Renacimiento italiano como reservorio de una tradición a la que aquí se representa como parte de un entretenimiento óptico y una curiosidad turística, en el mismo dispositivo fotomecánico que en esos mismos años trastocaría definitivamente la hegemonía de las bellas artes y sus vínculos, siempre tensos, con la reproductibilidad de las imágenes y las nociones de autor, original y estilo, entre otras.

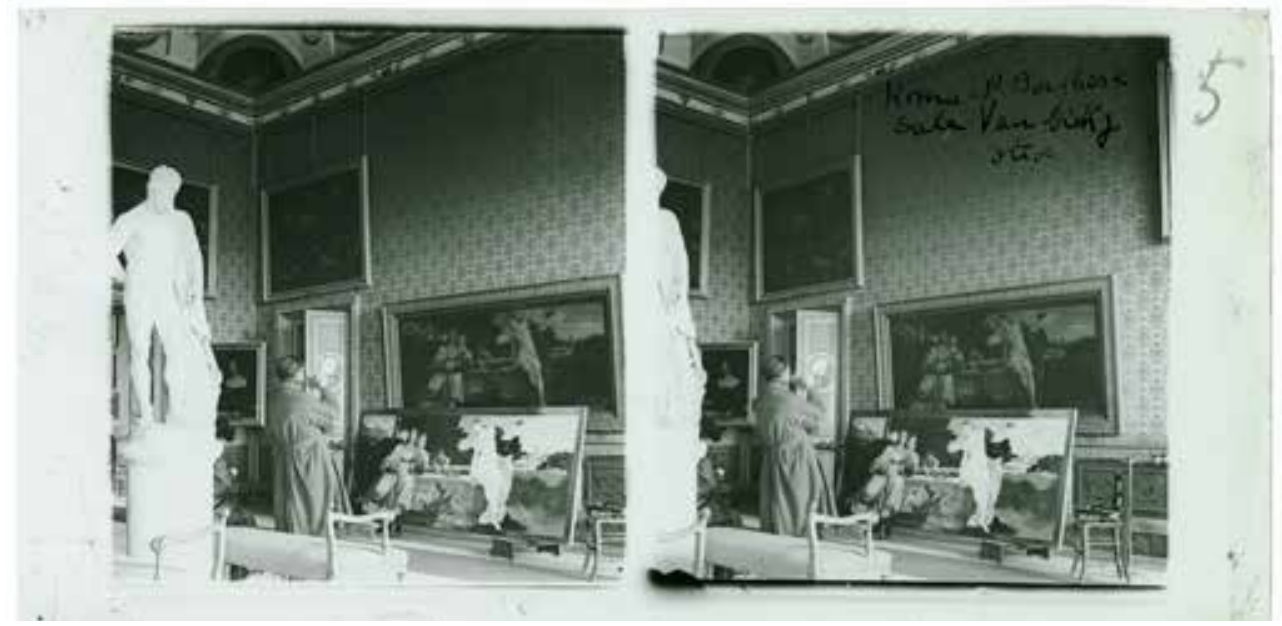

Figura 5. 5 Roma, P. Borghese, Sala Van Dyck y otros (s. f.), Bernardo Croce (c. 40, pl. 2). Fuente: Archivo CIFHA 


\section{MetodologíAs del ARCHIVO Y AUTORÍA}

Cabe señalar, por último, algunos problemas metodológicos que los archivos fotográficos de aficionados como este suelen oponer a todo intento de sistematización historiográfica, artística, museográfica o patrimonial. Parece razonable relacionar estos problemas con las propias nociones de fotografía amateur o fotografía de aficionados que, acuñadas a fines del siglo XIX para distinguir a la fotografía producida por fuera de la práctica profesional o comercial, se consolidaron como categorías históricas en el marco de un modelo epistemológico que se volvió hegemónico durante la segunda posguerra. Este modelo, impulsado desde los treinta por Beaumont Newhall y legitimado por instituciones como el Museum of Modern Arte (MoMA) (Phillips, 1997), concibió la historia de la fotografía desde una perspectiva modernista, como un proceso técnica y estéticamente progresivo estructurado en torno al accionar de un corpus limitado de autores destacados; pero ese esquema también, inevitablemente, dejó irresuelta su propia contradicción de fondo entre la necesidad de singularizar una parte de la producción fotográfica existente, por un lado, y, por el otro, la tendencia al anonimato y a la masividad que es inherente a la propia fotografía.

Resultó de ello un estado de cosas que fue señalado por historiadores como Michel Frizot (2009), quien hace algunos años señalaba la imposibilidad, o al menos las limitaciones evidentes, de rescatar archivos fotográficos de autores anónimos o ignotos sobre los que se proyecta un esquema conceptual que les resulta ajeno. Al no construirse un criterio de validación alternativo a aquel más ampliamente institucionalizado, señala este autor, se cae fácilmente en interpretaciones forzadas de materiales fotográficos cuyo análisis se organiza en torno a nociones provenientes del mundo del arte, como las de autor, estilo u obra. Si la práctica artística y teórica de los últimos cincuenta años puso reiteradamente en jaque la validez o al menos el alcance tradicional de estos conceptos, la fotografía fue un terreno particularmente apto para la exhibición de algunas de sus contradicciones más flagrantes. Desde las provocadoras afirmaciones de Susan Sontag (2006) sobre la carencia de estilo de las fotografías, o los cuestionamientos de Roland Barthes y de Michel Foucault a la categoría de autor (Irvin, 2005), hasta la problematización sistemática de la originalidad por los artistas apropiacionistas, la imagen analógica y mecánicamente reproducible puso especialmente en evidencia estas cuestiones, una y otra vez.

Los casos que Frizot (2009) analiza son un claro ejemplo de ello, al demostrar la pobreza conceptual con que algunas galerías, coleccionistas y museos exhibieron y publicaron en las últimas décadas archivos fotográficos familiares o de origen incierto y aun heterogéneo. Tales archivos fueron objeto de diversas operaciones de puesta en valor, basadas en la selección más o menos antojadiza de ejemplares sobre la base de su carácter estrafalario, curioso, técnicamente logrado —o en el caso contrario, desde la estética exotista del error, tan brillantemente criticada por Clément Chéroux (2013) — o su adecuación a los cánones indistintamente aplicados de la instantánea documental o de la fotografía de vanguardia. Si Frizot (2009) daba cuenta de un fenómeno que se remontaba a los años setenta, el más reciente caso de Vivian Maier nos recuerda que sus cuestionamientos están lejos de perder vigencia.

El médico Bernardo Croce fue un fotógrafo aficionado. Su producción alcanza picos de calidad técnica que se mantienen estables por tres décadas en una parte importante de su acervo. También produjo, en esos mismos años, centenares de placas subexpuestas, movidas, fuera de foco o con exposiciones dobles. La evidente habilidad para componer aprovechando al máximo los recursos provistos por el dispositivo estereoscópico es evidente en cerca de un millar de sus tomas, pero otras tantas exhiben resultados sumamente desparejos. Como otros viajeros y fotógrafos cuya masividad era todavía emergente en la sociedad de su época, se dejó sorprender y seducir por lo curioso, lo desconocido, lo monumental y lo banal, que convirtió, cámaras y visores mediante, en un espectáculo que regalar para sus amigos, su entorno familiar y descendencia. Tomó decisiones temáticas, de género, compositivas 
y técnicas en las que seguramente pesó la lectura de tratados y revistas como los mencionados al comienzo de este artículo, pero también un volumen igualmente incierto de instantáneas célebres, películas, obras de arte y fotografías familiares observadas en su casa o en las de sus amigos, en la misma red de sociabilidad en la que insertaría más tarde las imágenes que realizó o compró en sus andanzas por el mundo.

Nos queda de él, en todo caso, un acervo de casi cinco mil fotografías que documentan —todas y cada una por igual- mucho más que la intención, más o menos explícita o inexistente, de producir obras de arte, pruebas históricas o testimonios de la dicha familiar. Son, ante todo, testigos elocuentes del universo de expectativas, ambiciones, temores y anhelos con las que un habitante de Buenos Aires elaboró, en la primera mitad del siglo pasado, el mapa de referencias que consideró necesario para sentar su posición en el mundo que lo rodeaba. Su valor patrimonial, estético o histórico se desprende de todo lo que tenga para decirnos, que será, ante todo, lo que sepamos preguntarle.

\section{REFERENCIAS}

Becquer Casaballe, A. y Cuarterolo, M. A. (1983). Imágenes del Río de la Plata. Crónica de la fotografía rioplatense 1840-1940. Ciudad Autónoma de Buenos Aires, Argentina: Editorial del fotógrafo.

Benjamin, W. [1936] (1989). La obra de arte en la época de su reproductibilidad técnica. En Discursos interrumpidos I (pp. 15-57). Ciudad Autónoma de Buenos Aires, Argentina: Taurus.

Bibliografía. (julio de 1894). Revista Fotográfica llustrada del Río de la Plata, 1(11), 176.

Boure [sic por Bourée], H. (1929). Consejos a los estereoscopistas. Foto-Magazine, 3(32), 300-301.

Chéroux, C. (2013). Breve historia del error fotográfico. Ciudad de México, México: Vestalia Ediciones.

Crary, J. (2008). Las técnicas del observador. Visión y modernidad en el siglo XIX. Murcia, España: Cendeac.

Darrah, W. C. (1997). The World of Stereographs [El mundo de las estereografías]. Michigan, Estados Unidos: Land Yacht Press.

Donnadieu, A. L. (mayo de 1894). Observaciones sobre la separación en fotoestereoscopía. Revista Fotográfica llustrada del Río de la Plata, 1(9), 141-143.

Estereoscopía. Los anáglifos por virajes. (20 de febrero de 1930). Foto-Magazine, 3(36), 420 422.

Facio, S. (1995). La fotografía en la Argentina. Desde 1840 a nuestros días. Ciudad Autónoma de Buenos Aires, Argentina: La Azotea.

Frizot, M. (2009). El imaginario fotográfico. Ciudad de México, México: Vestalia Ediciones.

Irvin, S. (2005). Appropriation and Authorship in Contemporary Art [Apropiación y autoría en el arte contemporáneo]. British Journal of Aesthetics, 45(2), 123-137. https://doi. org/10.1093/aesthj/ayi015

Phillips, C. (1997). El tribunal de la fotografía. En G. Picazo y J. Ribalta (Comps.), Indiferencia y singularidad. La fotografía en el pensamiento artístico contemporáneo (pp. 59-98). Barcelona, España: MACBA.

Prensa estereoscópica. (julio de 1894). Revista Fotográfica llustrada del Río de la Plata, 1(11), 173.

Revista de periódicos. (enero de 1894). Revista Fotográfica llustrada del Río de la Plata, 1(5), 79-80.

Sontag, S. (2006). Sobre la fotografía. Ciudad de México, México: Alfaguara.

Tagg, J. (2005). El peso de la representación. Ensayos sobre fotografías e historias. Barcelona, España: Gustavo Gili.

Tell, V. (2017). El lado visible. Fotografía y progreso en la Argentina a fines del siglo XIX. San Martín, Argentina: UNSAM. 